\title{
Comparison of development methods based on UV/VIS spectrophotometry and ICP OES for the determination of iodine in pharmaceuticals
}

\author{
Amanda Ramos Della Fonte, Vitor de Araújo Freitas, Rosangela Cristina Barthus* \\ Departamento de Quimica, Centro de Ciencias Exatas, Universidade Federal do Espirito Santo, Vitoria-Brazil.
}

\begin{tabular}{l} 
ARTICLE INFO \\
\hline Article history: \\
Received on: $11 / 11 / 2015$ \\
Revised on: 04/01/2016 \\
Accepted on: $28 / 01 / 2016$ \\
Available online: $30 / 04 / 2016$ \\
\hline Key words: \\
UV-Vis spectrophotometry, \\
Sandell-Kolthoff reaction, \\
ICP OES, iodine.
\end{tabular}

\begin{abstract}
In this study, methods based on UV-Vis spectrophotometry (Sandell-Kolthoff reaction) and inductively coupled plasma optical emission spectrometry (ICP OES) were developed in order to determine iodine in pharmaceuticals. A simple preparation of samples, which consisted in the solubilization by means of ultrasound, was performed using pure water as solvent. The developed analytical methods were validated employing limit of detection, precision and accuracy. The recovery range is $101.0 \%-104.0 \%$ for the expectorant solutions, and $98.0 \%-102.0 \%$ for the supplements using the ICP OES technique. For the UV-Vis spectrophotometric method, the recovery range is $96.0 \%-98.0 \%$ for the expectorant solutions, and $96.0 \%-98.3 \%$ for the supplements. These methods are simple and accessible, and might be used in the pharmaceutical field.
\end{abstract}

\section{INTRODUCTION}

The development of an analytical methodology to determine iodine in pharmaceutical products is extremely important so as to ensure the quality and, therefore, safe use of such products. Among the functions of these products is iodine supplementation, which is one of the possible ways to obtain this element. Iodine is an essential micronutrient for the synthesis of triiodothyronine (T3) and thyroxine (T4) hormones, which are produced in the thyroid (Oliveira et al., 2012). These substances are used to provide a series of biochemical processes regulating the functioning of several human organs (Oliveira et al., 2012). Supplementation is essential especially during pregnancy and lactation periods, in which a larger amount of iodine is required. In general, an excess or a deficit of this element in the human body may lead to several health problems. Currently, there are several techniques utilized for determination of iodine in different types of matrices, such as flame atomic absorption spectrometry (FAAS) (Bermejo Barreira et al., 1999, Moreda et al., 2011, Yebra et al., 2010); total reflection X-ray fluorescence, TXRF (Varga, 2007); inductively coupled plasma

\footnotetext{
* Corresponding Author

Rosangela Cristina Barthus, Departamento de Quimica, Centro de Ciencias Exatas, Universidade Federal do Espirito Santo, Vitoria-Brazil. Email: barthus.rosangela@gmail.com
}

optical emission spectrometry (ICP OES) (Niedobova et al., 2005, Naozuca et al., 2003); inductively coupled plasma-mass spectrometry (ICP MS) (Mesko et al., 2010, Tagami et al., 2006); and voltammetry (He et al., 2003). Before applying these techniques, a sample preparation must be carried out, which is one of the most critical stages for methodology development. Procedures such as microwave-assisted combustion (Mesko et al., 2010), pyrohydrolysis (Taflick et al., 2012), extractions (Brown et al., 2012) and others can be found in the literature. The techniques and the sample preparation employed for this determination must be based on the complexity of the samples: the contents, the shape of the analyte chemical species, as well as the cost and the analytical quality required. In this study, a comparison between two different techniques was performed: the UV-Vis spectrophotometry, using the Sandell-Kolthoff reaction (Abouhiat et al., 2013, Jooster et al., 2010); and the inductively coupled plasma optical emission spectrometry (ICP OES). The interest in the use of ICP OES technique for this purpose is due to the fact that the usage of such equipment in routine analysis is becoming increasingly popular. Analysis of nonmetals like iodine is reported in few studies in the relevant literature. Therefore, even though this technique appears to be promising for such usage, it must be studied considering the challenges of its application to this element. 
For sample preparation, solubilization was performed by ultrasound using only pure water as solvent. It was discovered that the analysis of such products is possible without memory effect or analyte loss when using matrices such as those studied here.

This paper aims at developing methods for the determination of iodine in expectorant solutions and supplements, whose formulations correspond to the pharmaceuticals used mainly in the periods of pregnancy and lactation. The results of merit figures analyses allowed us to evaluate the quality of the methods. These studies also compare the methodologies proposed which are therefore, important features.

\section{MATERIALS AND METHODS}

\section{Chemicals}

All reagents were of analytical grade and used without previous purification treatment. The reagents potassium iodide, arsenic (III) oxide, Cerium (IV) sulfate, sulfuric acid and sodium hydroxide were from Sigma-Aldrich ${ }^{\circledR}$. Nitric acid and hydrochloric acid were from VETEC ${ }^{\circledR}$.

\section{Solutions used for UV-Vis spectrophotometry analyses.}

The following solutions were used: Solution of cerium (IV) $0.005 \mathrm{~mol} \mathrm{l}^{-1}$ solubilizing $0.42 \mathrm{~g}$ of cerium (IV) sulfate in $200.00 \mathrm{ml}$ of water and $6.25 \mathrm{ml}$ of sulfuric acid, followed by dilution with water to $250.00 \mathrm{ml}$. The arsenic (III) solution was prepared in concentration of $0.400 \mathrm{~mol} \mathrm{l}^{-1}$ with the addition of 1.00 $\mathrm{g}$ of arsenic (III) oxide and $1.50 \mathrm{~g}$ of sodium hydroxide in 200.00 $\mathrm{ml}$ of water, followed by the addition of $6.00 \mathrm{ml}$ of sulfuric acid and water until completing $250.00 \mathrm{ml}$. The water used in all procedures was treated by a deionization system Quimis ${ }^{\circledR}$ Q180, followed by a reverse osmosis system Quimis ${ }^{\circledR} \mathrm{Q} 342$.

\section{Pharmaceutical Samples}

The pharmaceutical products used in the analysis presented the following composition: Commercial expectorant solutions from different brands containing $100 \mathrm{mg}$ of potassium iodide in every $5 \mathrm{ml}$ of the product, such as plant extracts excipient, colorants and flavorings; the carrier was sorbitol or sucrose.

The supplements were obtained from compounding pharmacies those composition is identical to that of the commercial products used for supplementation during the period of pregnancy or lactation. Pharmaceutical 1 corresponds to $262 \mu \mathrm{g}$ of potassium iodide, $400 \mu \mathrm{g}$ of folic acid and $2 \mu \mathrm{g}$ of B12 vitamin, $0.50 \mathrm{mg}$ of starch and $0.50 \mathrm{mg}$ of lactose per capsule. Pharmaceutical 2 had the following composition: $320 \mu \mathrm{g}$ of potassium iodide, $400 \mu \mathrm{g}$ of folic acid, $2 \mu \mathrm{g}$ of B12 vitamin, 0.50 $\mathrm{mg}$ of starch, and $0.50 \mathrm{mg}$ lactose per capsule.

\section{Sample preparation}

During the pretreatment stage, all glassware and equipment used in the process were pre-washed and decontaminated by acid bath containing $5 \% \mathrm{HNO}_{3} \mathrm{v} \mathrm{v}^{-1}$ for $24 \mathrm{~h}$.
The analyses of expectorant solutions were diluted in pure water and kept in an ultrasound bath (Thornton ${ }^{\circledR}$ T14) at a fixedfrequency wave for $10 \mathrm{~min}$.

The final solution concentration was $0.500 \mathrm{mg} \mathrm{l}^{-1}$. In the supplement analyses, dilutions were performed in pure water of five capsules content, keeping them in an ultrasound bath for 30 minutes, followed by a vacuum filtration using glass fiber membranes (Marcherey Nagel ${ }^{\circledR}$ ). Subsequently, a dilution was performed until achieving the iodine concentration of $0.500 \mathrm{mg} \mathrm{l}^{-1}$. After the sample preparation, the $\mathrm{pH}$ of all solutions was determined using a pH-meter (MS Tecnopon).

\section{Instrumentation and UV-Vis spectrophotometry analyses.}

The analyses performed by UV-VIS spectrophotometry (Sandell-Kolthoff reaction) employed the pro-análise ${ }^{\circledR} 1100$ equipment. The analysis was processed with the addition of $500 \mu \mathrm{l}$ of the prepared sample, or standard solutions, or with the blank samples, followed by the addition of $1.00 \mathrm{ml}$ of arsenic (III) solution and, after 1 minute, $1.00 \mathrm{ml}$ of cerium (IV) solution. One minute after the last addition, the measurement was made with a spectrophotometer at $420 \mathrm{~nm}$.

\section{Instrumentation and ICP OES analyses}

The experiments by ICP OES were performed on an Optima 7000 device, Perkin Elmer ${ }^{\circledR}$, with double vision, equipped with shear gas (removal system of the cold plasma zone), solid state detector (CCD), and an optical system with pre-purging, which enabled the analysis in wavelengths in the range of VUV. The analytical conditions such as sample introduction flow, nebulizer gas flow, and plasma power were optimized using response surface methodology in order to improve the ICP analysis for the determination of iodine. Other conditions were described in Table 1.

Table 1: Operating conditions used in ICP OES with axial configuration.

\begin{tabular}{ll}
\hline Parameters & Conditions \\
\hline Vision & Axial \\
Nebulizer & Gemcone \\
Nebulization chambre & Cyclonic for aqueous \\
Injector & Alumina \\
Purge of the pre-optical system & High \\
Plasma gas flow rate $\left(1 \mathrm{~min}^{-1}\right)$ & 15.0 \\
Auxiliary gas flow rate $\left(1 \mathrm{~min}^{-1}\right)$ & 1.50 \\
Plasma power $(\mathrm{W}) *$ & 1315 \\
Nebulization gas flow rate $\left(1 \mathrm{~min}^{-1}\right)^{*}$ & 0.90 \\
Sample introduction Flow $\left(\mathrm{ml} \mathrm{min}^{-1}\right)^{*}$ & 2.62 \\
Spectral line & $206.163 \mathrm{~nm}$ \\
\hline
\end{tabular}

\section{Optimization of instrumental parameter conditions by} response surface methodology.

A Central composite design (CCD) with the three variables plasma power $\left(x_{\mathbf{1}}\right)$, nebulizer gas flow $\left(x_{\mathbf{z}}\right)$ and sample introduction flow $\left(x_{\mathbf{a}}\right)$, which are the most significant variables to be studied in experimental design, was applied for the optimization (Table 2). The dependent factor variable corresponds to the analytical signal. 
Table 2: Original and coded value of the independent variable (optimization).

\begin{tabular}{|c|c|c|c|c|c|c|}
\hline \multirow{3}{*}{ Factors } & \multirow{3}{*}{ Name } & \multicolumn{5}{|c|}{ Coded Value } \\
\hline & & -1 & $\mathbf{0}$ & 1.0 & -1.68 & +1.68 \\
\hline & & \multicolumn{5}{|c|}{ Original Value } \\
\hline $\mathrm{x} 1$ & Power (W) & 1100 & 1250 & 1400 & 1000 & 1500 \\
\hline $\mathrm{x} 2$ & Nebulization gas flow rate $\left(1 \mathrm{~min}^{-1}\right)$ & 0.6 & 0.8 & 1.0 & 0.5 & 1.1 \\
\hline $\mathrm{x} 3$ & Sample introduction Flow $\left(1 \mathrm{~min}^{-1}\right)$ & 1.9 & 2.3 & 2.6 & 1.7 & 2.7 \\
\hline
\end{tabular}

The mathematical model which related independent and dependent variables is given as:

$$
\begin{gathered}
Y=b_{0}+b_{1} x_{1}+b_{2} x_{2}+b_{3} x_{3}+b_{11} x_{1}^{2}+b_{22} x_{2}^{2}+b_{3 a} x_{3}^{2}+b_{12} x_{1} x_{2}= \\
1+b_{13} x_{1} x_{3}+b_{23} x_{2} x_{3}+b_{12 a} x_{1} x_{2} x_{3}+\varepsilon \ldots 1
\end{gathered}
$$

Where $\mathrm{Y}$ is a dependent variable (analytical signal obtained by ICP OES technique), $b_{0}$ is a constant, $b_{1}, b_{\mathbf{2}}, b_{3}$ are the linear coefficient, $b_{1 \mathrm{r}}, b_{2 \mathrm{z}}, b_{3 \mathrm{z}}$ are the quadratic coefficient, $b_{1 \mathrm{z}}, b_{1 \mathrm{a}}, b_{2 \mathrm{z}}$ and $b_{12 z}$ are the interaction coefficient, $x_{1} x_{2}, x_{3}$ are the coded values of the independent variables and experimental errors $(\varepsilon)$ are modeled by 1 .

\section{Quality evaluation of the proposed methods}

For evaluating the methods, the following validation parameters were employed: selectivity, linearity range, limit of detection, precision and robustness. For ICP OES method, the memory effect was also evaluated.

\section{RESULTS AND DISCUSSION}

Determination of iodine in pharmaceutical samples using UVVis spectrophotometry (Sandell-Kolthoff reaction)

\section{Sample preparation for the determination of iodine in pharmaceuticals}

One of the most critical stages for methodology development is the sample preparation. Some operations may develop, for example, the formation of $\mathrm{HI}$ and $\mathrm{I} 2$, allowing volatilization and absorption/adsorption over different materials under these conditions, which may generate problems to determine this element (Oliveira et al., 2012). Here, the preparation system of the expectorant sample consisted in the application of ultrasound in the sample that had undergone dilution in pure water. For the supplements, a previous filtration before obtaining the final concentration was necessary in order to eliminate undissolved solids. The $\mathrm{pH}$ values found for all the solutions and extracts were near 7.0. For that reason, it is suitable for our purpose since the chances of converting the iodide into volatile forms are very low in such conditions, which was corroborated by memory effects studies showed in validation results.

\section{Quality evaluation UV-Vis spectrophotometry (Sandell- Kolthoff reaction).}

\section{Selectivity}

This parameter evaluates the existence of signals derived from non-analyte components. In order to determine selectivity, analysis of the blank samples (supplements and expectorant solution containing sorbitol, expectorant solution containing sucrose) and calibration blank - pure water was performed in six replicates. From ANOVA test, the calculated F value was 2.59. The critical value of $\mathrm{F}$ is 3.03 with $95 \%$ of confidence; consequently matrix effect is absent.

\section{Detection limit}

The lowest concentration to be detected by the method, with at least $95 \%$ of confidence, is defined as the limit of detection (LOD). The definition of this figure of merit was performed through the analysis of the blank samples, and standard solutions in the blank samples. The lowest concentration of iodine that could be distinguished from the blank sample was $0.004 \mathrm{mg} \mathrm{l}^{-1}$, based on the $\mathrm{F}$ test ( $95 \%$ confidence).

\section{Linearity}

The linear range, regression equation, correlation coefficient, $\mathrm{F}$ test and Cochran test are given in Table 3. The linearity parameter is the ability of an analytical method to demonstrate that the sign results produced by the analysis are proportional to the concentration of analyte in the sample within the selected range. This connection is demonstrated by the development of a mathematical model (least-squares regression analysis) in which regression analysis reveals a good correlation. Another evaluation for model was made by ANOVA test, which proved the superiority of the regression in relation to the residues because the calculated value of $\mathrm{F}$ is higher than the critical $\mathrm{F}$ value (with $95 \%$ confidence). The Cochran test ( $\mathrm{C}$ test), which consists of the ratio between the largest variance and the variance of the sum of all calibration levels, was employed to evaluate the homoscedasticity of the model. The calculated value of $\mathrm{C}$ is lower to critical $\mathrm{C}$, and the replicates in all concentration levels of the calibration curve have generated similar variances. That is, the model is homoscedastic, and as a result, in this case, the leastsquares method can be employed.

Table 3: Statistical data of regression for iodine determination.

\begin{tabular}{lll}
\hline \multicolumn{1}{c}{ Parameters } & \multicolumn{1}{c}{ Spectrophotometric method } \\
\hline$\lambda \max$ & $420 \mathrm{~nm}$ & \\
Linearity range & $0.10-0.75 \mathrm{mg} \mathrm{l}^{-1}$ & \\
Regression equation & $\mathrm{Y}=-0.881 \mathrm{x}+0.0678$ & \\
Correlation coefficient $(\mathrm{r})$ & 0.999 & critical $F$ value 4.69 \\
$\mathrm{~F}$ test & calculated $F$ value 13,129 & critical $C$ value 0.684 \\
Cochran test & calculated $C$ value 0.533 & \\
\hline
\end{tabular}

The residues of the calibration curves are presented in figure 1, and the absence of trends and dispersibility can be observed because they have become random. 


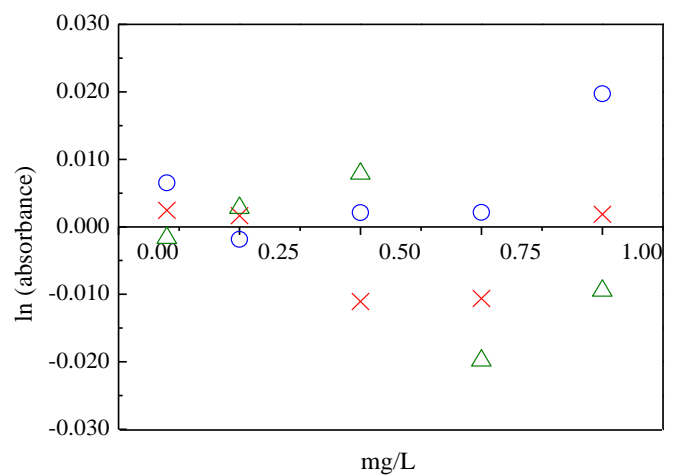

Fig. 1: Calibration curves residues for UV-Vis Spectrometric method

\section{Accuracy and Precision}

Accuracy is the agreement degree between the measured value and the expected value, and it can be evaluated through recovery tests, that is, the percentage of concentration found in the test compared to the present, or added, amount. In order to verify accuracy, the average recovery was calculated (analysis performed in triplicate), which resulted in, for the expectorant solutions, the following results: $97.0 \%$ (low-level), $98.0 \%$ (mid-level) and 96.0 $\%$ (high- level). For supplements, the following values: $98.3 \%$ (low-level), 98.1\% (mid-level) and 96.0\% (high-level). The precision, which is the repeatability, evaluates the dispersion degree of the analysis results under predetermined conditions and can be expressed through the coefficient of variation (CV). In the same tests with the standard solutions amid the expectorant blank solutions, we obtained the following coefficients of variation: 3.8 $\%$ (low-level), $3.2 \%$ (mid-level) and $4.3 \%$ (high- level). The coefficients of variation found for the supplements were: $3.1 \%$ (low level), $1.7 \%$ (mid-level) and $3.8 \%$ (high-level). The accuracy and precision corroborated the good performance of the method.

\section{Robustness}

Robustness is the measured capacity of the method to resist to small experimental variations to which it is easily susceptible. In the evaluation of this validation parameter, the pharmaceutical samples studied were analyzed using the solution of cerium (IV) PA Vetec ${ }^{\circledR}$ and another brand, and distinct purity degree reagents. Six real replicates with each cerium sulfate reagent were performed and $\mathrm{F}$ test applied. The $\mathrm{F}$ value obtained with the results, in both cases, was 1.51; the critical value of $F$ is 5.05 with $95 \%$ confidence. Therefore, it can be concluded that the change of brand / purity of the cerium (IV) sulfate reagent did not generate a significant change in the analysis results.

\section{Determination of iodine in pharmaceutical samples by ICP OES}

\section{Memory Effect Evaluation}

The memory effect refers to the adsorption / absorption of the analyte in the equipment accessories generating variations in the analytical signs. So as to avoid the memory effects, a cleansing in the system was performed using a blank solution (pure water) between analyzes. In order to verify possible memory problems and also to ensure the cleansing efficiency, the interspersed measures of the blank and the iodine standard solution of $4.00 \mathrm{mg}$ $\mathrm{I}^{-1}$ were observed. In the evaluation of the memory effect, it was noticed that the analyses of the blank and the interspersed standard solutions (five analyses for each solution) generated, for the standard solution, an average of $2312.68 \pm 54.41$ as intensity signal. The intensities in the blank measurements are not significant even after the aspiration of the standard solution. The intensities in the analysis of the patterns neither increased nor decreased considerably; they remained stabilized. As a result, no memory effect has been detected.

\section{Optimization of instrumental parameters of ICP OES for iodine determination.}

As iodine is a difficult element to ionize, it was necessary to optimize instrumental parameters of the ICP OES, such as plasma power, the nebulization gas flow, and the aspiration rate of the sample (which were the most significant in the analysis) so as to select a condition that was able to generate greater analytical signal (response).
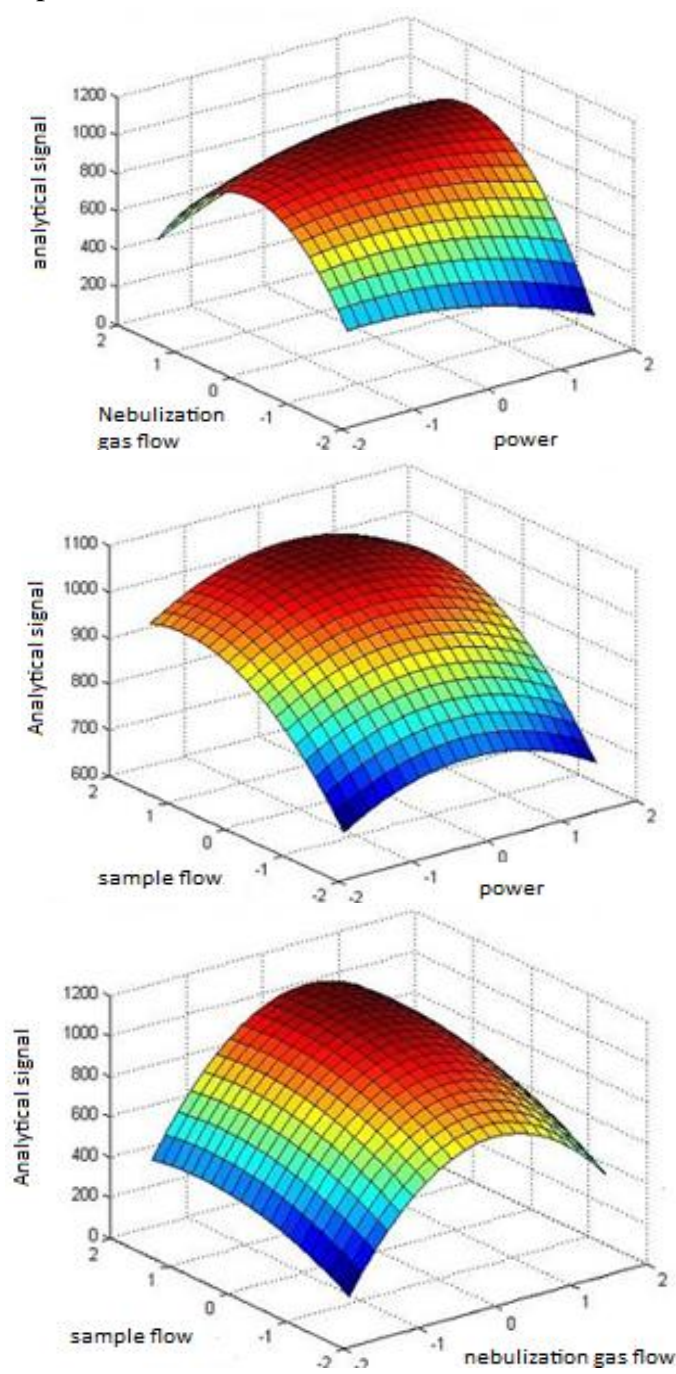

Fig. 2: Response surface (3D) showing the effect of the plasma power (x1), nebulization gas flow (x2) and sample introduction flow (x3) on the analytical signal. 
Thus, the variables were analyzed in different conditions according to central composite design. The mathematical model generated is demonstrated in equation 2 .

$Y=995+90.29 x_{2}+80.1 x_{3}-30.1 x_{1}^{2}-160.0 x_{2}^{2}-35.6 x_{3}^{2}+50.76 x_{1} x_{2} . .(2)$ Where: $x_{1}$ represents the plasma power factor, $x_{2}$ represents the nebulization gas flow, and $x_{3}$ represents the aspiration rate of the sample (sample introduction flow). The model was evaluated by ANOVA and it was verified that the model has a good adjustment and is capable of being applied for optimization purposes. Figure 2 shows the surface methodology response for the variables studied.

The optimized conditions obtained by equation 2 show that $2.62 \mathrm{ml} \mathrm{min}^{-1}, 0.901 \mathrm{~min}^{-1}$ and $1315 \mathrm{~W}$ are the best condition for sample introduction flow, nebulizer gas flow, and plasma power, respectively.

\section{Quality evaluation of ICP OES method}

Some validation parameters used in the analyses by ICP OES presented variations when compared with those used in the UV-VIS spectrophotometry, which are shown in the following sections. These validation parameters were used for the quality evaluation of the developed method based on the ICP OES technique, the same way performed before for the other method.

\section{Selectivity}

The selectivity of the method was first assessed through the analyses of the blank samples (supplements, expectorant solutions containing sorbitol, expectorant solutions containing sucrose) and calibration blank (pure water), and carried out in six replicates. The analysis of variance (ANOVA) was used in order to check the similarity among the results. The calculated value of $\mathrm{F}$ is 0.51 . The critical value of $\mathrm{F}$ is 3.03 ; therefore, there is no matrix effect.

\section{Detection limit}

For the ICP OES, the limits of detection (LOD) were calculated as described in the previous literature (Peixoto et al., 2012). The $\mathrm{LOD}=(3 \times \mathrm{BEC} \times \mathrm{RSD}) / 100$. In these expressions, RSD corresponds to the relative standard deviation for 10 measurements of the blank, and BEC corresponds to the background equivalent concentration, which was experimentally determined under the optimized conditions. The lowest concentration detected in the pharmaceuticals by this method (LOD) was $0.33 \mathrm{mg} \mathrm{l}^{-1}$.

\section{Linearity}

The linear range, regression equation, correlation coefficient, $\mathrm{F}$ test and Cochran test are given in Table 4. The model obtained shows a good correlation, and ANOVA test corroborated the new good model. According to Cochran test, it was verified that the model is homoscedastic and least square regression can be used.

Another consideration regarding the results of the calibration curve can be obtained by residual plot, as shown in figure 3 . It can be observed that the residue triplicates are random; they do not have a tendency and therefore assert the suitability of the model.

Table 4: Statistical data of regression for iodine determination.

\begin{tabular}{lll}
\hline Parameters & ICP OES & \\
\hline Linearity range & $2.00-11.47 \mathrm{mg} \mathrm{l}^{-1}$ & \\
Regression equation & $\mathrm{Y}=436.40 \mathrm{x}-0.890$ & \\
Correlation coefficient $(\mathrm{r})$ & 0.998 & \\
F test & calculated $F$ value 6,777 & critical F value 4.49 \\
Cochran test & calculated $C$ value 0.370 & critical $C$ value 0.684 \\
\hline
\end{tabular}

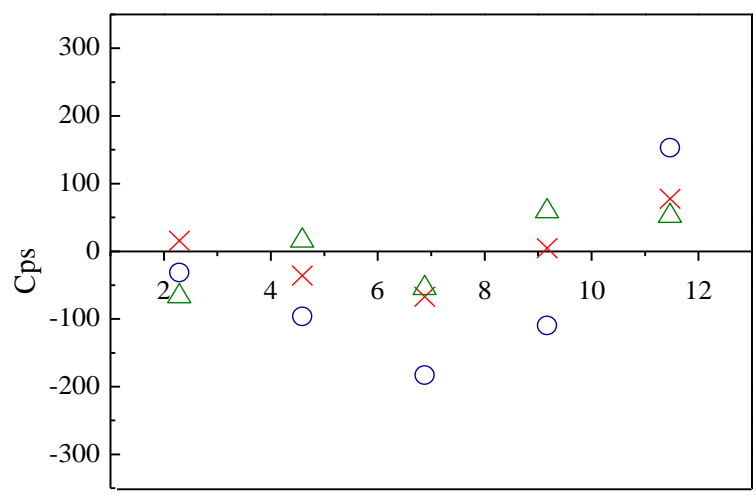

$\mathrm{mg} / \mathrm{L}$

Fig. 3: Curve calibration residues for ICP OES method

\section{Accuracy and Precision}

In the accuracy test with the blanks of the expectorant solutions, the average recoveries were: $104.0 \%$ (low-level), $101.1 \%$ (mid-level) and $101.0 \%$ (high-level). The average recoveries of the standard solutions in the blank of the supplements were: $98.1 \%$ (low-level), $102.0 \%$ (mid-level) and $100.2 \%$ (high-level), which shows the good performance of the method. In the precision (repeatability) evaluation of the standard solutions in the blank of the expectorant solutions, the following coefficients of variation were found: 3.1 (low-level), 2.3 (midlevel) and 5.8 (high-level). In the analysis of the standard solutions in the blank of the supplements, the coefficients of variation were: $6.5 \%$ (low-level), $5.6 \%$ (mid-level), 6.9\% (highlevel). Therefore, it also demonstrates good performance of the method.

\section{Robustness}

In ICP OES, the robustness of the plasma is evaluated. This parameter is intended for verifying the existence of changes in the atomic and ionic excitement stages when the solution of the sample is aspirated. For this purpose, the relation between the intensities generated in the magnesium determination in the spectral line $280 \mathrm{~nm}$ by the line $285 \mathrm{~nm}$ is evaluated. For this assay, one aliquot of magnesium standard solution was added to an aqueous medium, achieving the concentration of $0.50 \mathrm{mg} \mathrm{l}^{-1}$. The intensity in the ion line divided by intensity in the atomic line generated an average ratio of $9.16 \pm 0.07$ (A total of five tests for each line). As the average value is above 8.00, we can conclude that the operational conditions used in ICP OES generated good 
plasma stability. The analysis results of the samples are shown in Table 5 .

Table 5: Iodine determination results by using Spectrophotometry and ICP OES.

\begin{tabular}{ccc}
\hline Samples & $\begin{array}{c}\text { UV-Vis Spectrophotometry } \\
\text { Sandell-Kolthoff reaction }\end{array}$ & ICP OES \\
\hline Expectorant 1 & $99.22 \pm 3.17$ & $97.82 \pm 4.25$ \\
Expectorant 2 & $92.90 \pm 2.12$ & $93.25 \pm 3.35$ \\
Expectorant 3 & $96.45 \pm 3.00$ & $97.17 \pm 3.64$ \\
Expectorant 4 & $99.60 \pm 2.38$ & $94.24 \pm 4.02$ \\
Supplement 1 & $250.52 \pm 7.28$ & $239.38 \pm 10.54$ \\
Supplement 2 & $286.26 \pm 3.12$ & $307.46 \pm 5.62$ \\
\hline
\end{tabular}

$\mathrm{mg}$ in $5 \mathrm{~mL}$ of the product. $\mu \mathrm{g}$ per capsule.

It can be observed that the result of the sample analyses, in both methods, were compatible. Another important fact is that all sample standard deviations were low (results in triplicate), and the trends were above 87\%; that is, the pharmaceuticals have concentrations consistent with those written in the labels.

\section{Comparison of methods}

The spectrophotometric method with fixed time is inexpensive, fast and reasonably easy to perform. As far as ICP OES method is concerned, its expenditure is higher because of the equipment and the gases required. But it is worth mentioning that the equipment can also assist many other testing in the pharmaceutical field, allowing analysts to evaluate the results of reliable testing, the financial cost and the applicability of the method in order to choose the best for each situation. The analysis results of the samples revealed similar responses produced by the methods.

\section{CONCLUSION}

The analytical quality of the methods for the determination of iodine in pharmaceutical products was evaluated, in both cases, by preparing the samples performing a dilution in aqueous solution. The development methods present similar response and their applicability depends on the analysis demand, time consumption, equipment availability and reagents used in each technique. The procedures are simple and can be used in the pharmaceutical field.

\section{ACKNOWLEDGEMENTS}

We are grateful to NCQP/UFES for supporting this study and A.R.D Fontes V.A. Freitas would also like to thank Capes for the scholarship.

\section{REFERENCES}

Abouhiat FZ, Henríquez C, Horstkotte B, Yousfi F, Cerda V, A miniaturized analyzer for the catalytic determination of iodide in seawater and pharmaceutical samples. Talanta, 2013; 108: 92-102.

Barros Neto B, Scarmínio IS, Bruns RE.2010. Como fazer experimentos , Bookman, , Porto Alegre.
Bermejo-Barrera P, Aboal-Somoza M, Bermejo-Barrera A, Atomic absorption spectrometry as an alternate technique for iodine determination (1968-1998). J. Anal. At. Spectrom, 1999; 14: 10091018 .

Brown CF, Geiszler KN, Vickeman TS, Extraction and quantitative analysis of iodine in solid and solution matrixes. Anal. Chem. 2005; 77: 7062-7066.

He Q, Fei J, Hu H, Voltammetric method based on an ionpairing reaction for the determination of trace amount of iodide at carbonpaste electrodes., Anal. Sci. 2003; 19: 681-686.

Jooster PL, Strydom E, Methods for determination of iodine in urine and salt. Best Pract. Res. Clin. Endocrinol. Metab., 2010; 24: 79-80.

Mesko MF, Mello PA, Bizzi CA, Dressler VL, Knapp G, Flores EMM, Iodine determination in food by inductively coupled plasma mass spectrometry after digestion by microwave-induced combustion. Anal. Bioanal. Chem., 2010; 398:1125-1131.

Moreda-piñeiro A, Romarís-Hortas V, Bermejo-Barrera PB, A review on iodine speciation for environmental, biological and nutrition fields, J. Anal. At. Spectrom., 2011; 26:2145-2147

Naozuka J, Veiga MAMS, Oliveira PV, de Oliveira E, Determination of chlorine, bromine and iodine in milk samples by ICPOES , J. Anal. At. Spectrom., 2003; 18: 917-921.

Niedobová E, Machát J, Otruba V, Kanický V, Vapour generation inductively coupled plasma optical emission spectrometry in determination of total iodine in milk. J. Anal. At. Spectrom., 2005; 20: 946-949.

Oliveira AA, Nóbrega JA, Pereira Filho ER, Trevizan LC, Avaliação de ICP OES com configuração axial ou radial para determinação de iodo em sal de cozinha. Quim. Nova, 2012; 35: 1299 1305 .

Peixoto RGA, Oliveira A, Cadore S, Multielemental Determinations in Chocolate Drink Powder Using Multivariate Optimization and ICP OES, J.Agric. Food. Chem., 2012; 60: 8117-8118

Taflick T, Duarte AF, Flores ELM, Antes GF, Paniz JNG, Flores EMM, Dressler VL. Determination of Bromine, Fluorine and Iodine in Mineral Supplements using Pyrohydrolysis for Sample Preparation. J. Braz. Chem. Soc., 2012; 23: 488-489.

Tagami K, Uchida S, Hirai I, Tsukada H, Takeda $\mathrm{H}$, Determination of chlorine, bromine and iodine in plant samples by inductively coupled plasma-mass spectrometry after leaching with tetramethyl ammonium hydroxide under a mild temperature condition. Anal. Chim. Acta, 2006; 570: 88-92.

Varga I, Iodine determination in dietary supplement products by TXRF and ICP-AES spectrometry. Microchem. J, 2007;85:127-131.

Yebra MC, Bollaín MH, A simple indirect automatic method to determine total iodine in milk products by flame atomic absorption spectrometry. Talanta, 2010; 82: 828-829.

\section{How to cite this article:}

Fonte ARD, Freitas VA, Barthus RC. Comparison of development methods based on UV-VIS spectrophotometry and ICP OES for the determination of iodine in pharmaceutical. J App Pharm Sci, 2016; 6 (04): 022-027. 